\section{Fix databases that fail with two surnames}

Scientific databases widely used in anglophone countries should cater for contributors from cultures that do not follow the format of a given name followed by one family name. Such inconsistencies cause problems for academic referencing and mask scientists' cultural diversity in the scientific record.

In Spain, for example, people have two surnames, one from each parent. One of us, who should be indexed as Mira Pérez, J., is often wrongly cited as Pérez, J. M.. Spanish scientists use hyphens or drop a name to avoid such errors. Asian scientists can face a similar problem (see Nature 451, 766-767; (2008); N. Puniamoorthy et al. Nature 452, 530; 2008): in Indonesia, for example, many have only one name (see go.nature.com/3xgf6v).

The anglophone naming system can also intrude on other aspects of research, including grant applications and conference registration. EasyChair is an example of a conference-managing system that has diversified to accommodate people with two surnames or none at all (https:// easychair.org).

Jorge Mira Pérez University of Santiago de Compostela, Spain. jorge.mira@usc.es

M. Carmen Parafita Couto Leiden University, the Netherlands.

\section{African swine fever ravaging Borneo's wild pigs}

African swine fever has breached the island of Borneo, where it is wiping out populations of the wild bearded pig Sus barbatus. First confirmed in early February, the outbreak has driven a precipitous decline in this species in less than two months. Field sites in the east of the Sabah region are reporting a complete absence of live pigs in forests. Local extinctions across swathes of Borneo are a realistic prospect.

Bearded pigs are listed as vulnerable by the International Union for Conservation of Nature. They are seen as 'ecosystem engineers' in the Bornean rainforest, where they are one of the most abundant species of mammal. Bearded pigs can be legally hunted under permit, and are an important source of animal protein for many communities.

The African swine fever virus is already island-hopping across southeast Asia, threatening 11 species of endemic pig, including the Sulawesi warty pig (Sus celebensis). Opportunities to control the disease in wildpig populations are limited. Vaccines for domestic pigs are still in development, so the best hope for stemming loss of the wild animals could be to protect isolated populations in geographically defensible locations.

Robert M. Ewers Imperial College London, Ascot, UK.

r.ewers@imperial.ac.uk

Senthilvel K. S. S. Nathan

Sabah Wildlife Department, Kota

Kinabalu, Sabah, Malaysia.

Peter A. K. Lee Sabah Department of Veterinary Services, Kota

Kinabalu, Sabah, Malaysia.

\section{Brazil: video inspires young women to work in solar energy}

The solar-energy industry in Brazil is booming. It employs 43,000 people, only $20 \%$ of whom are women. Just $12 \%$ of these women have technical and scientific roles. To encourage girls to enter these professions, the Brazilian Women's Network in Solar Energy (Rede Brasileira de Mulheres na Energia Solar, or MESol) has released a video called Women of Energy.

The video (see go.nature. com/3ucs9zj) highlights women working in renewable-energy research, teaching and industry. It aims to address the perceived lack of female role models in this sector. As one teenager who watched it said: “I didn't know so many women work in this area."

A diverse workforce improves creativity, innovation and decision-making, and also boosts profits (see go.nature. com/39safwv and M. W. Nielsen et al. Proc. Natl Acad. Sci. USA

114, 1740-1742; 2017). Efforts to achieve gender equity require companies to make changes to management, leadership and the personal development of employees.

The video was produced with support from the German Cooperation for Sustainable Development as part of Brazil's Professionals for the Energy of the Future initiative.

Aline Kirsten Vidal de Oliveira* Brazilian Women's Network in Solar Energy, Florianópilis, Brazil. rb.mulheresenergiasolar@gmail. com

*On behalf of 5 correspondents; see go.nature.com/3vmb4kn

\section{Five principles for scientists on social media}

To enable the information sharing, networking and serendipitous encounters that we would normally experience at physical conferences and seminars, many scientists are looking to improve their online engagement through social media. Based on my experiences, I offer five suggestions.

First, see and be seen: communication is two-way, so listen, too. Second, select and specialize: focus on those things that suit you; there's only so much you can do. Third, serve: think about where you can add most value. Fourth, socialize: don't forget about relationships just because they're digital. Fifth, strategize: make social media part of your overall communication strategy, even if it's just emerging.

I follow these principles by responding to posts I am tagged in. I tweet only on topics that I feel able to discuss. I stick to Facebook for more personal engagement, to Twitter for sharing interesting developments in research and practice, and to LinkedIn for the occasional announcement of new research and events. I use my accounts to showcase my own work, yes, but also to amplify others' contributions and promote our collective domain.

Challenges regarding scientists' engagement will remain post-pandemic (Nature $589,155-157 ; 2021)$. Social media can help us to overcome these and find new routes to scholarly impact and visibility.

Marcel Bogers Eindhoven University of Technology, the Netherlands. m.l.a.m.bogers@tue.nl 